\title{
Monte carlo simulation of different positron emitting radionuclides incorporated in a soft tissue volume
}

\section{Simulación de Montecarlo de diferentes radionúclidos emisores de positrones incorporados en un volúmen de tejido blando}

\author{
Hernán Olaya Dávila ${ }^{a}$ \\ Héctor Fabio Castro Serrato ${ }^{b}$ \\ Segundo Agustín Martínez Ovalle ${ }^{c^{*}}$
}

Recepción: 17 de marzo 2016

Aceptación: 29 de diciembre 2016

\begin{abstract}
Monte Carlo calculations were carried out with radioactive sources of monoenergetic positron-emitters used in compounds, like FDG $\left({ }^{18} \mathrm{~F}\right)$, Acetate $\left({ }^{11} \mathrm{C}\right)$, and Ammonium $\left({ }^{13} \mathrm{~N}\right)$, were incorporated into a soft tissue volume, in the aim to estimate the type of particles produced their energies, their mean free paths, and the absorbed dose at different distances with respect to the center of the volume. The volume was modeled with a radius larger than the maximum range of positrons in order to produce $0.511 \mathrm{MeV}$ annihilation gamma-ray photons. With the obtained results the absorbed dose, in various organs and tissues able to metabolize different radiopharmaceutical drugs, can be estimated. The simulation code used was Geant 4.
\end{abstract}

Keywords: Positrons, Absorbed dose, Monte Carlo simulation.

\section{Resumen}

Se llevaron a cabo cálculos por el Método Monte Carlo con diferentes compuestos de radionucleidos emisores de positrones, tales como el FDG $\left({ }^{18} \mathrm{~F}\right)$, acetato de carbono $\left({ }^{11} \mathrm{C}\right)$, amonio $\left({ }^{13} \mathrm{~N}\right)$, etc, los cuales fueron incorporados en un volumen de tejido blando, con el propósito de estimar el tipo de partículas producidas y sus energías, los caminos libres medios y las dosis absorbida de radiación a diferentes distancias con respecto al centro del volumen. El volumen de tejido fue modelado con un radio más grande que el alcance máximo de los positrones, luego de producirse el proceso de aniquilación emitiendo fotones de $0.511 \mathrm{MeV}$. Se obtuvieron resultados de dosis absorbida y alcances máximos para varios órganos y tejidos y diferentes radiofarmacos. El código de simulación utilizado fue el Geant4.

Palabras clave: Positrones, Dosis absorbida, simulación Monte Carlo

\footnotetext{
${ }^{a}$ Grupo de Física Nuclear Aplicada y Simulación, Universidad Pedagógica y Tecnológica de Colombia, Tunja, Colombia.

${ }^{\mathrm{b}}$ Grupo CRYOMAG, Universidad Nacional de Colombia, Bogotá D.C, Colombia.

*Autor de correspondencia: s.agustin.martinez@uptc.edu.co
} 


\section{Introduction}

The remarkable progress of computers and software, miniaturization and better detector efficiency lead to continuous improvement of X-ray CT, especially in reducing radiation doses in patients. The Monte Carlo method is considered to be a powerful tool to simulate a physical phenomenon of radiation interaction with the matter and obtain a precise estimation of several physical parameters of a real situation $[1,2]$.

The Monte Carlo method used to simulate the radiation interaction with matter allows understanding the energy delivered into the volume of interest, and to know the dynamics of the particles produced, how are their trajectories, the mean free path and the maximum range in relation to the properties of the emitting radionuclide. In nuclear medicine application the positron-emitting radionuclide is attached to a particular molecule and later is incorporated into the body through inhalation, injection, or ingestion [3, 4].

Positron Emission Tomography (PET) is a technique in the field of nuclear medicine where a patient or a living creature who has been previously administrated small quantities of radioactive material through inhalation, injection or ingestion is metabolized into a tissue or organ and then the positrons emitted from the nucleus interact with electrons of the medium producing annihilation gamma photons [5]. The diagnostic image is formed by the emission of gamma photons in opposite directions that reach the PET detector array. Having an array of detectors configured ring-shaped, reconstructs the volume image based on distributed positrons and therefore in vivo measurements can determine the location and size of the lesion.

PET technique allow the detection of vascular and physiological diseases of the heart in real time, detect pathologies in early stages in people with Alzheimer's disease, Down Syndrome, etc. In addition, PET can be combined with other techniques such as computerized tomography $\mathrm{CT}$ and make more accurate diagnoses by combining the metabolic image with the anatomical image [6]. Before interacting with the electrons, positrons delivered its energy to the medium through collisions and when they have reach an energy of $1.022 \mathrm{MeV}$ they annihilate with electrons to form two photons of $511 \mathrm{keV}$, that trave- ling in opposite directions, about $180 \pm 0.5$ degrees [7]. The mean free path of positrons is responsible for the resolution of the diagnostic image. The lower the path before annihilation, volume interactions occur will be smaller, improving image quality $[8,9]$. See Figure 1.

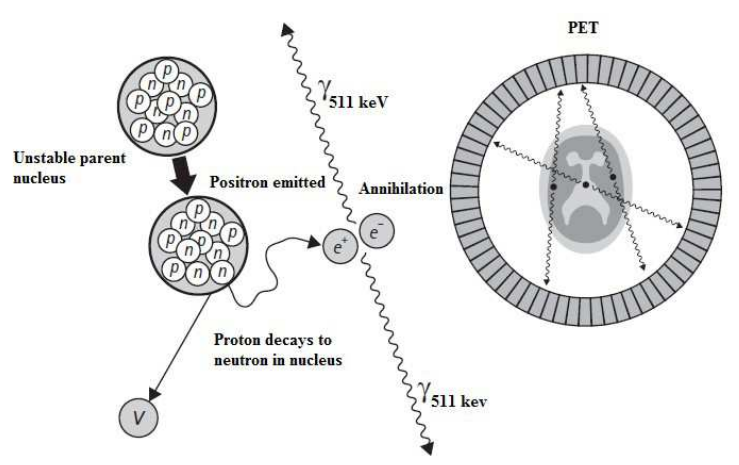

Figure 1. Annihilation process and gamma photons production.

The spatial resolution is also improved by the sensitivity and size of PET detectors. Annihilation processes can be lost in the detection if they fail to reach the detectors or whether electronics of coincidence window record an event as no true. Basically, when achieve lower path before annihilation, it will have information more precise about spatial location of the lesion and the outline of the volume of interest will delimit with more accuracy, allowing discard normal metabolic processes compared with potential tumor growths $[10,11]$.

The radioactive isotopes used in the PET are produced in a medical cyclotron in which usually a high energy proton beam is fired into an appropriate target. To produce ${ }^{18} \mathrm{~F}$ and ${ }^{18} \mathrm{O}$ water target undergoes the nuclear reaction ${ }^{18} \mathrm{O}(\mathrm{p}, \mathrm{n}){ }^{18} \mathrm{~F}$, indicating that a proton (p) is absorbed and a neutron (n) lost. The most common cyclotron configuration for PET is the negative ion design, which consist of two "dee" electrodes, which are about $1 \mathrm{~m}$ in diameter. Subsequently, radionucleide is taken to a radiochemistry laboratory, where they are combined with a chemical substance called tracer for latter administration. The mainly used radiotracers are shown in Table1, [12].

The purpose of this work was to determine the behavior of positrons from different emitting radionuclides with respect to its interaction with a volume of soft tissue, performing a statistical mean free path and the maximum range of the particles in or- 
Table 1. Main isotopes used in PET [3].

\begin{tabular}{cccc}
\hline Isotope & Tracer & Physiological process & Main application \\
\hline \hline${ }^{11} \mathrm{C}$ & Methionine & Protein Synthesis & Oncology \\
${ }^{11} \mathrm{C}$ & Raclopride & D2 Receptor & Movement disorder \\
${ }^{13} \mathrm{~N}$ & Ammonia & Blood Perfusion & Myocardial perfusion \\
${ }^{15} \mathrm{O}$ & Water/Dioxise & Blood Perfusion & Brain activation \\
${ }^{18} \mathrm{~F}$ & Fluorine Ion & Bone Metabolism & Oncology \\
${ }^{18} \mathrm{~F}$ & Fluorine deoxyglucose & Glucose Metabolism & Oncology Neurology Cardiology \\
\hline \hline
\end{tabular}

der to assess what kind of radionuclide from the point physically it is more convenient according to the size of the lesion. In this work was used Geant4 Monte Carlo simulation code [13].

\section{Materials and Methods}

The work was carried out using the Geant 4 code in the model designed for the Monte Carlo calculations with spheres of $10 \mathrm{~mm}$-radius, considering that sphere radius must be greater than maximum range of positrons used in nuclear medicine for water, Assuming that the most maximum range isotope used in nuclear medicine is ${ }^{15} \mathrm{O}$ with $8.2 \mathrm{~mm}$ and to ensure that the origin of all annihilation photons are within the water sphere. The materials of elemental spheres were chosen: water, muscle, adipose tissue and compact bone tissue, the components by weight they are taken from [11].

An isotropic radioactive source with spherical shape of $0.2 \mathrm{~mm}$ of diameter is located in the center of the sphere with 10.000 initial radioactive nuclei. Positrons interact with the matter creating ionizations and delivering energy until to produce the annihilation gamma photons. Subsequently, the simulation data are sent in ROOT software for processing and analysis of multiple interactions.

In the Figure $2 \mathrm{a}$ it shows the simulation with 10 decays, in the Figure $2 b$ it shows the simulation with 3 only decays of ${ }^{18} \mathrm{~F}$ in water with the aim of seeing the trajectories of positrons (broken lines) and gamma photons (straight lines).

List physical reference Geant4 LBE 5.3 was used because allows information about the decay processes at the same time that positrons are emitted. With this feature we can know the history of events during the positrons interactions until the positron annihilation with electrons can be estimated [13].

Results for various positron emmiting radionu-

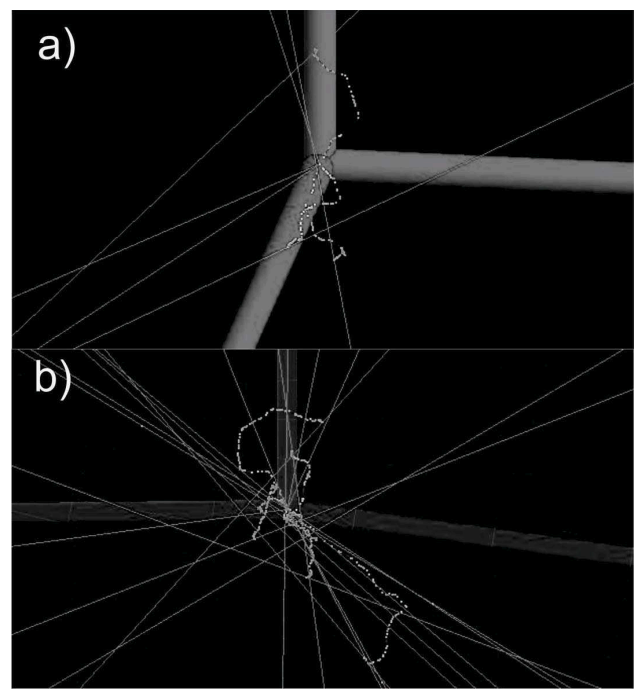

Figure 2. Simulation decays in ${ }^{18} \mathrm{~F}$.

clides and several tissues were compared in relation to energy deposited into sphere mass to determine the dose absorbed by the tissue [4]

\section{Results}

In the Figure 3 it show the average range of positrons emitted from ${ }^{18} \mathrm{~F},{ }^{11} \mathrm{C}$ and ${ }^{15} \mathrm{O}$, we might show at the center of each sphere the intensity and the length lines that represent the region where positrons delivered its energy based on initial energy of positrons. Below are shown the maximum length and average distance calculated through Gaussian fitting.

As the statistics of the data obeys a Gaussian distribution, the Full Half Maximum FWHM= $2 \sqrt{2 \ln 2 \sigma}=2.355 \sigma$ where $\sigma$ is the standard desviation. The FWHM corresponds to average range of positrons and $4.291 \sigma$ corresponds to maximum length reached by positrons [15]. In the Figure 3 can be seen the difference of trajectories of positrons for each positron emitting isotope.

Simulation data are stored in ROOT software [16] 


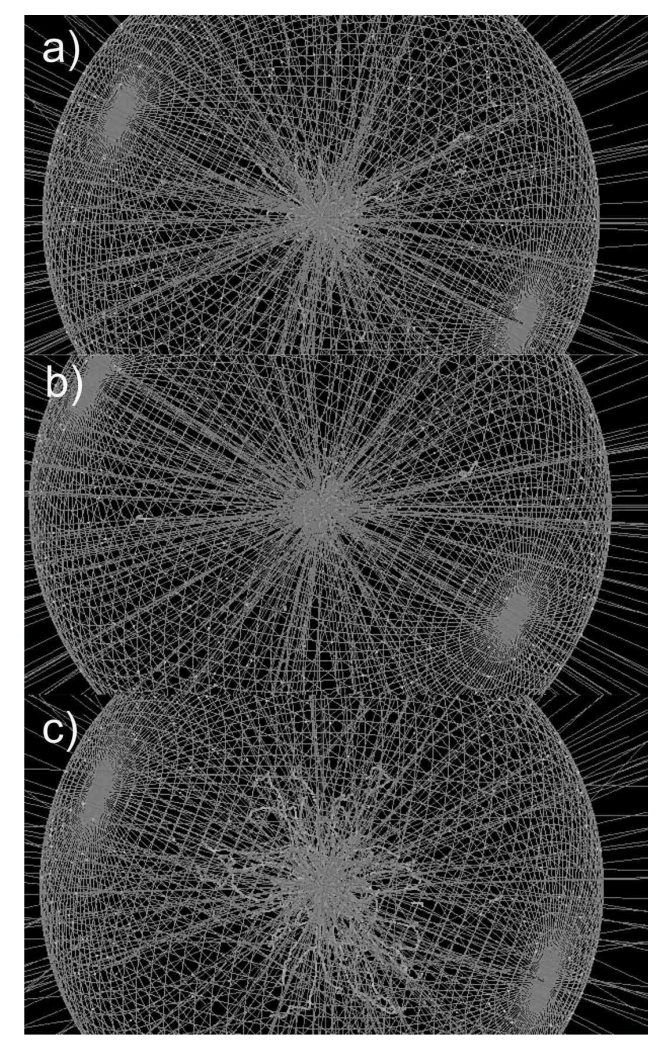

Figure 3. Simulation of several positron sources into a water sphere and its maximum length a) ${ }^{18} \mathrm{~F}=2.4 \mathrm{~mm}$ b) ${ }^{11} \mathrm{C}=5.0 \mathrm{~mm} \mathrm{c)}{ }^{15} \mathrm{O}=8.2 \mathrm{~mm}$.

and are shown the results in following histograms, see Figure 4. In Figure 4 shows the largest frequencies are given for shorter maximum lengths. It is clear to see that as much energy delivered by positrons in a small range and the largest contribution is obtained by ${ }^{18} \mathrm{~F}$.

The relation between maximum traveled length in water sphere and compact bone for ${ }^{18} \mathrm{~F}$ is 1.880 , ${ }^{11} \mathrm{C}$ is 1.673 and ${ }^{15} \mathrm{O}$ is 1.920 , this meaning that there is a relationship between tissue density and maximum length. A higher density of tissue decreases the maximum length. In Table 2 shown the maximum lengths in different tissues.

In Figure 5 the functional relationship between the energy of positrons corresponding to the three radionuclides simulated ${ }^{18} \mathrm{~F},{ }^{11} \mathrm{C}$ and ${ }^{15} \mathrm{O}$ and the maximum length of the positrons have a linear behavior. Allowing predict the range of positrons for any me-dium in terms of energy. Taking account decay time for each radionuclide and the relationship between the number of positrons simulated and the activity was evaluated the absorbed dose into the volume. The results are shown at the Table 3.

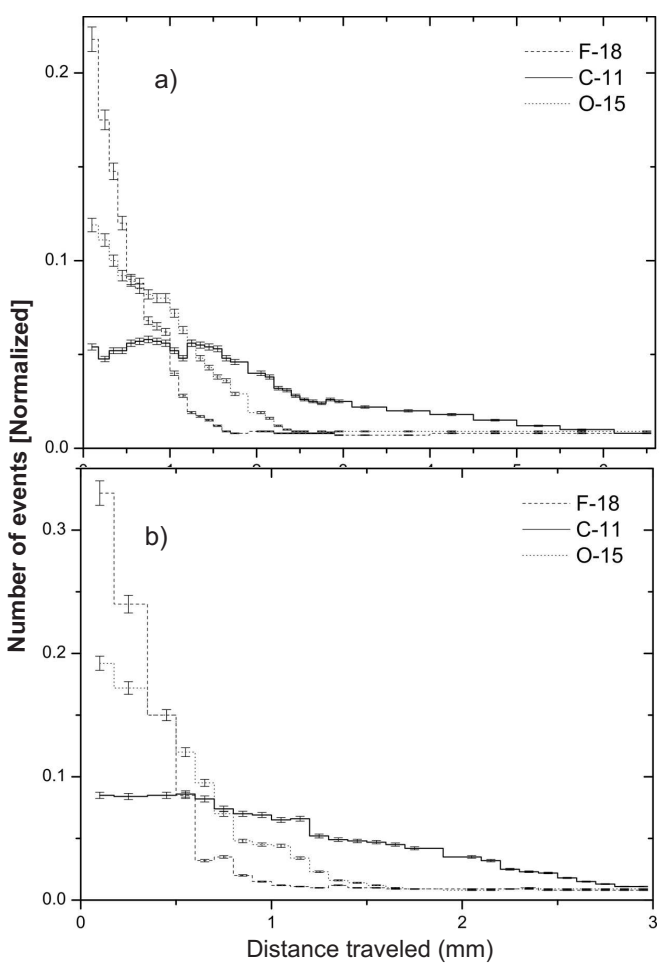

Figure 4. Figure 4. The maximum distance traveled by positrons in a sphere of $10 \mathrm{~mm}$ radius. (a) water (b) compact bone.

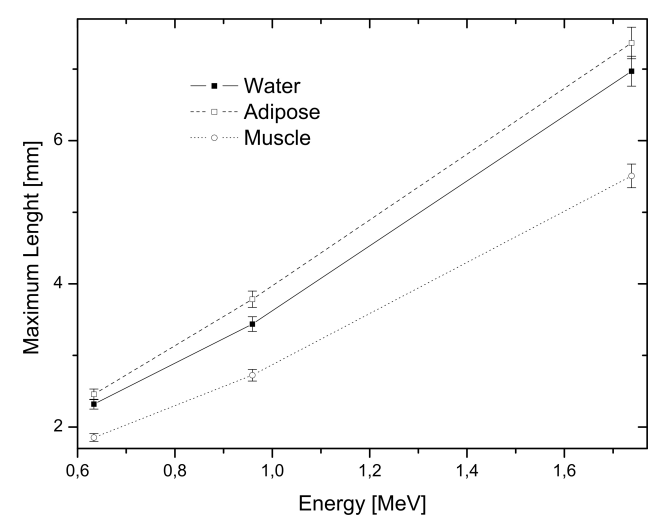

Figure 5. Relation between positron energy and maximum length for blood, adipose and muscle tissue).

This work can be extended to situations where knowing the volume and density of a tumor the radiopharmaceutical covers fully the region of interest not exceeding the amount of radioactive material in order to obtain an accurate diagnosis reducing the absorbed dose to the patient and the workers that delivered it. According to the results shown in Figure 5 it can be determined that the range of the positrons are almost linear with respect of their energy and the maximum displacement occurs in adipose tissue.

The absorbed dose into the volume depends of initial energy of positrons. The ${ }^{18} \mathrm{~F}$ due to have lo- 
Table 2. Maximum traveled lengths of positrons in different tissues.

\begin{tabular}{|c|c|c|c|c|}
\hline Isotope & Water & Adipose Tissue & Muscle Tissue & Compact Bone \\
\hline & \multicolumn{4}{|c|}{$[\mathrm{mm}]$} \\
\hline${ }^{18} \mathrm{~F}$ & $2.319 \pm 0.003$ & $2.457 \pm 0.003$ & $1.854 \pm 0.003$ & $1.233 \pm 0.002$ \\
\hline${ }^{11} \mathrm{C}$ & $3.438 \pm 0.003$ & $3.785 \pm 0.003$ & $2.723 \pm 0.003$ & $2.055 \pm 0.002$ \\
\hline${ }^{15} \mathrm{O}$ & $6.970 \pm 0.003$ & $7.365 \pm 0.003$ & $5.508 \pm 0.003$ & $3.630 \pm 0.002$ \\
\hline
\end{tabular}

Table 3. Absorbed dose in a distance from center of sphere.

\begin{tabular}{cccc}
\hline Isotope & Distance & Dose rate & $\begin{array}{l}\text { Dose integrated } \\
\text { in 10 minutes }\end{array}$ \\
\hline \hline & {$[\mathrm{mm}]$} & {$\left[\mathrm{mGy} \cdot \mathrm{h}^{-1}\right]$} & {$[\mathrm{mGy}]$} \\
\cline { 2 - 4 }${ }^{18} \mathrm{~F}$ & 2 & $0.356 \pm 0.01$ & $0.119 \pm 0.01$ \\
${ }^{11} \mathrm{C}$ & 3 & $0.427 \pm 0.01$ & $0.142 \pm 0.01$ \\
${ }^{15} \mathrm{O}$ & 6 & $0.608 \pm 0.01$ & $0.203 \pm 0.01$ \\
\hline \hline
\end{tabular}

west energy compared with ${ }^{11} \mathrm{C}$ and ${ }^{15} \mathrm{O}$ allows reduce the absorbed dose in a tissue. See Table 3.

In situations where its known the volume and density of a tumor, the radiopharmaceutical chosen must to cover fully the region of interest not exceeding the amount of radioactive material in order to obtain an accurate diagnosis reducing the absorbed dose to the patient and the workers that delivered it.

\section{Conclusions}

One of the important factors in the spatial resolution of a PET system is the maximum length of positrons, the shorter the range the higher the resolution. According to the results ${ }^{18} \mathrm{~F}$ is $48 \%$ shorter than ${ }^{11} \mathrm{C}$ and $31 \%$ shorter than ${ }^{18} \mathrm{O}$, which allows to conclude that ${ }^{18} \mathrm{~F}$ offers a better alternative for the study of tumors of small volumes, this is one of the reasons for the widespread use of FDG. The other isotopes are very useful for studies involving larger volumes such as cardiac perfusion and brain diseases. See Table 1.

Using different positron emitters is established that type of radionuclide it is needed for each kind of lesion and its volumetric configuration. The Monte Carlo method can accurately assess the maximum and averages ranges for any tissue and generally a lot of materials that are defined in the database Geant 4 simulation code or they can also be defined in the code starting from its elemental chemical composition.

\section{References}

[1] W. Belinato, W.S. Santos, C.M.M. Paschoal, D.N. Souza, "Monte Carlo simulations in multi-detector CT (MDCT) for two PET/CT scanner models using MASH and FASH adult phantoms", Nuclear Instruments and Methods in Physics Research Section A: Accelerators, Spectrometers, Detectors and Associated Equipment, vol. 784, pp. 524-530, 2015.

[2] ImXgam group, "Centre de Physique des Particles de Marseille (CPPM). Available in:", http://www.cppm.in2p3.fr/rubrique.php3?id_ rubrique $=185 \&$ id_parent $=7 \&$ lang $=$ fr, $[$ Reviewed on January 2015].

[3] S. Nicol, Étudeet construction d'un tomographe TEP/TDM pour petitsanimaux, combinant modules phoswich á scintillateurs et détecteur à pixels hybrids. Thèse de Doctorat Université de la Mediterranée, Aix -Marseille II, 2010.

[4] A. Granov, L. Tiutin, T. Schwarz (Editors), Positron Emission Tomography. Springer-Verlag Berlin Heidelberg, 2013.

[5] A. Iagaru, A. Kalinyak, J. E. McDougall, "I. R. F-18 FDG PET/CT in the management of thyroid cancer", Clinical Nuclear Medicine, vol. 32, pp. 690-695, 2007.

[6] International Atomic Energy Agency, "Quality assurance for PET and PET/CT systemsQuality assurance for PET and PET/CT systems", IAEA- Health Series No. 1, Viena, 2009.

[7] R. Badawi,"Introduction to PET physics", http://depts.washington.edu/nucmed/IRL/pet_ intro/.January, 2009. 
[8] G.B. Saha, "Centre de Physique des Particles de Marseille (CPPM). Available in:", The Cleveland Clinic Foundation, USA. Springer, 2012.

[9] S. F. Barrington, M. N. Maisey, R. L. Wahl, "Atlas of Clinical positron Emission Tomography", American Journal of Neuroradiology, vol. 28, pp. 993, 2007.

[10] E. L. Kramer, J. P. Ko, F. Ponzo, K. Mourtzikos. Positron Emission Tomography and Computed Tomography: A Disease-Oriented Approach. New York. 2009.

[11] D. L. Bailey, D. W. Townsend, P. E. Valk, M. N. Maisey (Editors), Positron Emission Tomography. Springer-Verlag Berlin Heidelberg, 2005.

[12] ICRP-89. International Commission on Radiological Protection. Basic Anatomical and Physiological Datafor Use in Radiological Protection: Reference Values, 2002.

[13] H. R. Vega Carrillo, "Neutron energy spectra inside a PET cyclotron vault room", Nuclear Instruments and Methods in Physics Research Section A: Accelerators, Spectrometers, Detectors and Associated Equipment, vol. 463, pp. 375-386, 2001.

[14] G. Collaboration, “Geant4 User's Guide for Application Developers. Accessible from the GEANT4 web page [1]", Version geant4, 9, 2012.

[15] W. Luo, E. Anashkin, C. G. Matthews, "Performance evaluation of a PEM scanner using the NEMA NU 4-2008 small animal PET standards", IEEE Transactions on $\mathrm{Nu}$ clear Science, vol. 57, pp. 94-103, 2010.

[16] P. Arce, J. I. Lagares, L. Harkness, D. PerezAstudillo, M. Canadas, P. Rato, A. Diaz, "Gamos: A framework to do Geant4 simulations in different physics fields with an userfriendly interface", Nuclear Instruments and Methods in Physics Research Section A: Accelerators, Spectrometers, Detectors and Associated Equipment, vol. 735, pp. 304-313, 2014. 